\title{
In Vitro and In Vivo Comparison of Selected Ga-68 and Zr-89 Labelled Siderophores
}

\author{
Milos Petrik, ${ }^{1}$ Chuangyan Zhai, ${ }^{2}$ Zbynek Novy, ${ }^{1}$ Lubor Urbanek, ${ }^{3}$ Hubertus Haas, ${ }^{4}$ \\ Clemens Decristoforo ${ }^{2}$ \\ ${ }^{1}$ Institute of Molecular and Translational Medicine, Faculty of Medicine and Dentistry, Palacky University, Hnevotinska 5, CZ-77900, \\ Olomouc, Czech Republic \\ ${ }^{2}$ Clinical Department of Nuclear Medicine, Medical University Innsbruck, Innsbruck, Austria \\ ${ }^{3}$ Laboratory of Growth Regulators, Centre of the Region Hana for Biotechnological and Agricultural Research, Institute of Experimental \\ Botany AS CR \& Palacky University, Olomouc, Czech Republic \\ ${ }^{4}$ Division of Molecular Biology/Biocenter, Medical University Innsbruck, Innsbruck, Austria
}

\begin{abstract}
Purpose: Some $\left[{ }^{68} \mathrm{Ga}\right]$ siderophores show promise in specific and sensitive imaging of infection. Here, we compare the in vitro and in vivo behaviour of selected Ga-68 and Zr-89 labelled siderophores.

Procedures: Radiolabelling was performed in HEPES or sodium acetate buffer systems. Radiochemical purity of labelled siderophores was determined using chromatography. Partition coefficients, in vitro stability and protein binding affinities were determined. Ex vivo biodistribution and animal imaging was studied in mice.

Results: Certain differences among studied siderophores were observed in labelling efficiency. Protein binding and stability tests showed highest stabilities and lowest protein binding affinities for Ga-68 and $\left[{ }^{89} \mathrm{Zr}\right]$ triacetylfusarinine C (TAFC). All studied Ga-68 and $\left[{ }^{89} \mathrm{Zr}\right]$ siderophores exhibited a similar biodistribution and pharmacokinetics in mice with the exception of $\left[{ }^{89} \mathrm{Zr}\right]$ ferrioxamine E (FOXE).

Conclusions: $\mathrm{Zr}-89$ and $\left[{ }^{68} \mathrm{Ga}\right]$ siderophores showed analogous in vitro and in vivo behaviour. Tested $\left[{ }^{89} \mathrm{Zr}\right]$ siderophores could be applied for longitudinal positron emission tomography (PET) studies of fungal infections and especially TAFC for the development of novel bioconjugates.
\end{abstract}

Key words: Siderophores, Gallium-68, Zirconium-89, PET, Imaging

\section{Introduction}

Siderophores are high affinity, iron-selective chelators produced by almost all bacteria, fungi and some plants $[1$, 2]. They serve as carrier molecules transporting iron across the microbial cell membranes, thus representing an excellent

Electronic supplementary material The online version of this article (doi:10.1007/s11307-015-0897-6) contains supplementary material, which is available to authorized users.

Correspondence to: Milos Petrik; e-mail: milospetrik@seznam.cz source of iron for many microorganisms. Iron is an essential nutrient for all cells and plays an important role also in microbial virulence [3]. Under iron-restricted conditions, some microorganisms secrete siderophores into the environment where they collect iron from various sources and deliver it into the producing organism [4]. In some species, specialized siderophores are synthesized, which are not excreted and serve as a unique iron storage form. Siderophores and their analogues have found wide application in agriculture and in medicine [5]. In medicine, siderophores have shown potential in applications like selective drug delivery; treatment of diseases, e.g., 
thalassemia, malaria and sickle cell disease; cancer therapy and imaging cancer and infection $[5,6]$.

Some Gallium-68 (Ga-68) labelled siderophores have demonstrated their use as specific agents for imaging Aspergillus infection [7]. Gallium $\left(\mathrm{Ga}^{3+}\right.$; ionic radius $=62 \mathrm{pm})$ and iron $\left(\mathrm{Fe}^{3+}\right.$; ionic radius $\left.=64 \mathrm{pm}\right)$ are structurally similar and have similar coordination properties. Ga-siderophore complexes are recognized by cellular transporters and receptors on bacterial cells allowing the complex to enter inside the microbial cell. Ga-68 is a radioactive isotope of gallium and has in recent years gained a lot of attention in the field of nuclear medicine for molecular imaging using positron emission tomography (PET) $[8,9]$. It is a short-lived positron emitter (half-life $=67.7 \mathrm{~min}$ ) that can be produced from a long shelf-life and cost-effective $\left[{ }^{68} \mathrm{Ge}\right] /$ $\left[{ }^{68} \mathrm{Ga}\right]$ generator system. The relatively short half-life of Ga68 can be a limitation especially in longitudinal studies. This deficit can be resolved using longer-lived positron-emitting radionuclides such as $\mathrm{Cu}-64, \mathrm{I}-124, \mathrm{Y}-86, \mathrm{Nb}-90$ or $\mathrm{Zr}-89$ [10].

The interest in Zirconium-89 (Zr-89) has increased over the last years as it displays almost ideal properties allowing imaging of biological processes at late time-points after the tracer application [11]. Even though Zr-89 has comparably low positron abundance and due to the long half-life results in higher radiation dose, it allows long-term follow-up especially of slowly accumulating biomolecules such as antibodies, nanoparticles and other large biomolecules both for preclinical and clinical applications, thereby complementing Ga-68 with its limitations of a very short half-life. Zr-89 can be produced in a cyclotron in large quantities and at high radionuclidic purity (99.99\%) [12]. It decays with a half-life of $78.4 \mathrm{~h}$ via both positron emission (23\%) and electron capture (77 \%). The relatively low positron energy of $396.9 \mathrm{keV}$ results in high image resolution [13]. The preferred oxidation state of zirconium is +4 with an ionic radius of $72 \mathrm{pm}$, also similar to the ferric iron.

In our previous studies, we have shown that different siderophores can be labelled with Ga-68 [14]. We have also demonstrated that $\left[{ }^{68} \mathrm{Ga}\right]$ triacetylfusarinine $\mathrm{C}$ (TAFC) and $\left[{ }^{68} \mathrm{Ga}\right]$ ferrioxamine E (FOXE) are able to detect Aspergillus fumigatus infection in a rat infection model using PET imaging $[7,15]$ and that $\left[{ }^{68} \mathrm{Ga}\right] \mathrm{TAFC}$ is highly specific to A. fumigatus in vitro [16]. Desferrioxamine B (FOXB), a hydroxamate siderophore, is the most commonly used bifunctional chelator for coordination of $\mathrm{Zr}-89^{4+}$. Several preclinical proof-of-principle studies have been conducted using FOXB to label antibodies with $\mathrm{Zr}-89$, but the in vivo stability of this complex remains an issue [17]. Our aim in this study was to evaluate the potential of alternative siderophores for radiolabelling with $\mathrm{Zr}-89$ and as imaging agents for Aspergillus infections. We also wanted to investigate any potential differences between the resulting $\mathrm{Zr}-89$ complexes and the respective Ga- 68 complexes; the differences in charge $\left(\mathrm{Zr}^{4+}\right.$ vs. $\left.\mathrm{Ga}^{3+}\right)$ could impact complex stability and other properties such as lipophilicity. We have investigated this issue and report here the in vitro and in vivo properties of selected $\mathrm{Zr}-89$ and Ga-68 labelled siderophores (Fig. 1).

\section{Materials and Methods}

\section{Chemicals}

All commercially available reagents were used as supplied with no further purification. Siderophores were purchased from EMC microcollections $\mathrm{GmbH}$ (Tubingen, Germany). $\left[{ }^{68} \mathrm{Ga}^{-} \mathrm{Cl}_{3}\right.$ was eluted from a $\left[{ }^{68} \mathrm{Ge}\right] /\left[{ }^{68} \mathrm{Ga}\right]$ generator (Eckert \& Ziegler Eurotope $\mathrm{GmbH}$, Berlin, Germany) with $0.1 \mathrm{~N} \mathrm{HCl}$ using the fractionated elution approach. Zr-89 in $1 \mathrm{M}$ oxalic acid was produced by the BV Cyclotron VU (Amsterdam, The Netherlands) and distributed by PerkinElmer (Boston, USA).

\section{Siderophores Radiolabelling and Quality Control}

Ga-68 labelled siderophores were prepared as previously described [14]. Radiolabelling of siderophores with $\mathrm{Zr}-89$ was performed using 9-11 $\mu \mathrm{l}$ of $\mathrm{Zr}-89$ in $1 \mathrm{M}$ oxalic acid (7-12 MBq) and neutralized with $10 \mu \mathrm{l} 1 \mathrm{M} \mathrm{Na}_{2} \mathrm{CO}_{3}$, then mixed with $100 \mu \mathrm{l}$ of HEPES buffer $(0.5 \mathrm{M}, \mathrm{pH}=7)$ and $20-50 \mu \mathrm{l}$ of an aqueous solution of desferrisiderophores $(1 \mu \mathrm{g} / \mu \mathrm{l})$. The reaction mixture was allowed to react at room temperature (RT) for $90 \mathrm{~min}$. Alternatively, direct incubation of 9-11 $\mu \mathrm{l} \mathrm{Zr-89}$ in $1 \mathrm{M}$ oxalic acid with $30-40 \mu \mathrm{l}$ of sodium acetate $(155 \mathrm{mg} / \mathrm{ml}$ in water) mixed with $20-50 \mu \mathrm{l}$ of desferrisiderophores dissolved in water $(1 \mu \mathrm{g} / \mu \mathrm{l})$ was performed. Incubation times (15-20 min) and temperature (RT or $80{ }^{\circ} \mathrm{C}$ ) were varied. Radiochemical purity (RCP) of labelled siderophores was determined on reverse-phase high-performance liquid chromatography (RP-HPLC) using a gradient system as described previously [15]. $\left[{ }^{89} \mathrm{Zr}\right]$ siderophores were additionally analysed by thin-layer chromatography (ITLC-SG/50 mM EDTA), in which $\left[{ }^{89} \mathrm{Zr}\right]$ siderophores remained at the origin and unbound $\mathrm{Zr}-89$ moved with the solvent front.

\section{In Vitro Characterization of Radiolabelled Siderophores}

Partition Coefficient DeterminationRadiolabelled siderophore in $0.5 \mathrm{ml}$ phosphate-buffered saline (PBS) $\mathrm{pH}=7.4$ was added to $0.5 \mathrm{ml}$ octanol and the mixture was vigorously vortexed for $15 \mathrm{~min}$. The aqueous and organic solvents were separated by centrifugation and $50 \mu \mathrm{l}$ aliquots of both layers were collected and measured in the automatic gamma counter (WIZARD ${ }^{2}$; PerkinElmer, Waltham, USA). $\log P$ values were calculated from obtained data (mean of $n=6)$.

Protein BindingProtein binding studies were performed by incubating radiolabelled siderophore $(1-2 \mu \mathrm{g} / 150 \mu \mathrm{l})$ in fresh human serum $(850 \mu \mathrm{l})$ and in PBS $(850 \mu \mathrm{l})$ (control) at $37{ }^{\circ} \mathrm{C}$ for various time points $\left(30,60\right.$ and $120 \mathrm{~min}$ for $\left[{ }^{68} \mathrm{Ga}\right]$ siderophores and 1,4 and $24 \mathrm{~h}$ for $\left[{ }^{89} \mathrm{Zr}\right]$ siderophores). After incubation, $25 \mu \mathrm{l}$ of the sample was separated by size-exclusion chromatography 


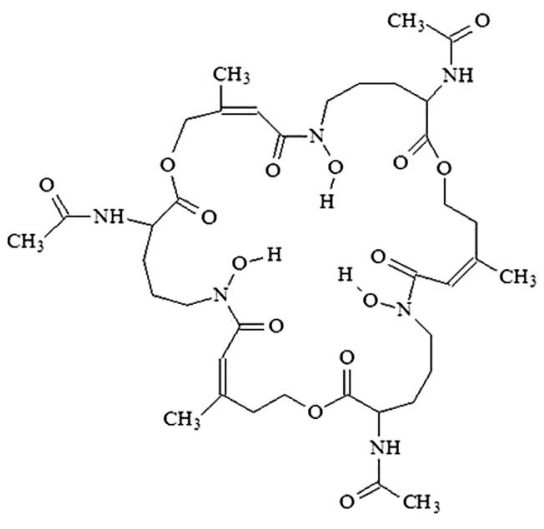

Triacetylfusarinine $\mathrm{C}$ (TAFC)

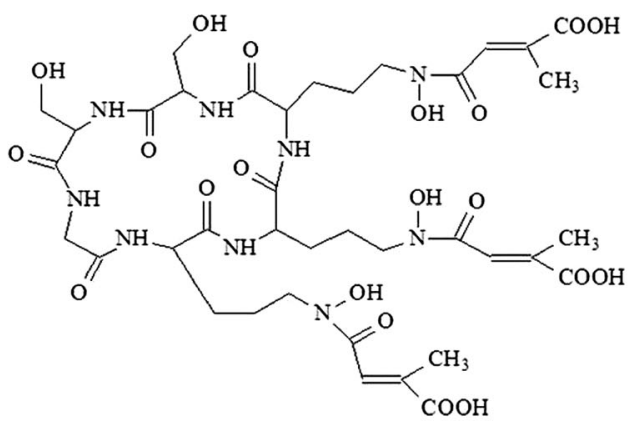

Ferrichrome A (FCHA)<smiles>[2H]ON1CCCCCNC(=O)CCC(=O)N(O[2H])CCCCCNC(=O)CCC(=O)CCC1=O</smiles>

Ferrioxamine E (FOXE)

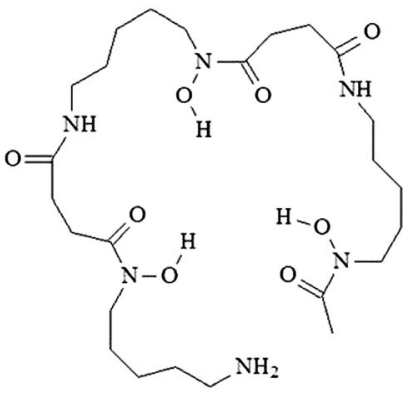

Ferrioxamine B (FOXB)

Fig. 1 Structures of studied siderophores.

(MicroSpin $^{\mathrm{TM}}$ G-50 Columns; Sephadex G-50 (GE Healthcare, Buckinghamshire, UK)) by centrifugation at $2000 \times g$ for $2 \mathrm{~min}$. Protein binding of radiolabelled siderophores was determined by measuring the activity distributed between the column (non proteinbound) and the eluate (protein-bound) using the automatic gamma counter.

Stability StudiesThe in vitro stability of radiolabelled siderophores $(3-6 \mu \mathrm{g} / 100 \mu \mathrm{l})$ was tested in fresh human serum $(300 \mu \mathrm{l})$ and a $6 \mathrm{mM}$ solution of diethylenetriaminepentaacetic acid (DTPA) $\mathrm{pH}=7(100 \mu \mathrm{l})$ at $37^{\circ} \mathrm{C}$ at several time points $(30,60$ and $120 \mathrm{~min}$ for $\left[{ }^{68} \mathrm{Ga}\right]$ siderophores and 1,4 and $24 \mathrm{~h}$ for $\left.{ }^{89} \mathrm{Zr}\right]$ siderophores). After incubation, human serum samples were precipitated with acetonitrile or ethanol, centrifuged $(2200 \times g$, $3 \mathrm{~min}$ ) and the supernatant analyzed. Degradation of the radiolabelled siderophore complexes was evaluated by RP-HPLC. Samples of the DTPA solutions were directly injected onto the HPLC.

\section{Animal Experiments}

All animal experiments were conducted in accordance with regulations and guidelines of the Czech Animal Protection Act (No. 246/1992), and with the approval of the Czech Ministry of Education Youth and Sports (MSMT-18933/2013-1), and the institutional Animal Welfare Committee of the Faculty of Medicine and Dentistry of Palacky University in Olomouc. The studies were performed using female Balb/c mice (Anlab, Prague, Czech Republic).

\section{Biodistribution in Balb/c Mice}

Biodistibution of radiolabelled siderophores was studied in female Balb/c mice ( 8 weeks old). Ga-68 and Zr-89 labelled siderophores (1-2 MBq/mouse, corresponding to $0.1-0.2 \mu \mathrm{g}$ of siderophore per mouse) were injected retro-orbitally (r.o.). Animals were sacrificed by cervical dislocation 30 and 90 min post-injection (p.i.). Organs and tissues (blood, spleen, pancreas, stomach, intestine, kidneys, liver, heart, lung, muscle and femur) were removed and weighed. The amount of radioactivity in the samples was measured in an automatic gamma counter. Results were expressed as percentage of injected dose per gram organ $(\% \mathrm{ID} / \mathrm{g})$.

\section{PET Imaging of Radiolabelled Siderophores in Balb/c Mice}

PET and computed tomography (CT) images were acquired with an Albira PET/SPECT/CT small animal imaging system (Bruker Biospin Corporation, Woodbridge, CT, USA). Female Balb/c mice were r.o. injected with radiolabelled siderophores in a dose of 5$10 \mathrm{MBq}$ corresponding to $0.5-1 \mu \mathrm{g}$ of siderophore per mouse. Animals were anaesthetized with isoflurane (FORANE, Abbott Laboratories, Abbott Park, IL, USA) (2\% flow rate) and positioned prone head first in the Albira system before the start of imaging. 
Static PET/CT imaging was carried out 5, 30 and 90 min p.i. for both Ga-68 and Zr-89 labelled siderophores. Animals injected with $\left[{ }^{89} \mathrm{Zr}\right]$ siderophores were also imaged $4 \mathrm{~h}$ p.i. A 5 -min PET scan (axial FOV $148 \mathrm{~mm}$ ) was performed, followed by a CT scan (axial FOV $65 \mathrm{~mm}, 45 \mathrm{kVp}, 400 \mu \mathrm{A}$, at 600 projections). Dynamic imaging was carried out immediately after the injection of radiolabelled siderophore for $90 \mathrm{~min}$ (5 min PET scan per frame). Scans were reconstructed with the Albira software (Bruker Biospin Corporation, Woodbridge, CT, USA) using the maximum likelihood expectation maximization (MLEM) and filtered backprojection (FBP) algorithms. After reconstruction, acquired data was viewed and analyzed with PMOD software (PMOD Technologies Ltd., Zurich, Switzerland). 3D images were obtained using VolView software (Kitware, Clifton Park, NY, USA). Animal imaging was performed for all studied siderophores except for ferrichrome A (FCHA).

\section{Results}

\section{Radiochemistry}

The labelling conditions as well as labelling efficiency were slightly different for studied desferrisiderophores. Desferritriacetylfusarinine C (TAFC) and desferriferichrome A (FCHA) were labelled with Ga-68 in sodium acetate buffer at room temperature for 15 min with an RCP greater than $98 \%$. Radiolabelling of desferrioxamine E (FOXE) and desferrioxamine B (FOXB) with Ga-68 was performed in sodium acetate buffer at $80{ }^{\circ} \mathrm{C}$ for 20 min with an RCP greater than $98 \%$. Zr-89 labelling of all studied siderophores using $\mathrm{Na}_{2} \mathrm{CO}_{3}$ for neutralization followed by incubation with the siderophore in HEPES buffer $(\mathrm{pH}=7)$ required incubation times of more than 90 min at RT with the RCP greater than $98 \%$. Interestingly, direct incubation of $\left[{ }^{89} \mathrm{Zr}\right]$ oxalate with the corresponding siderophore in sodium acetate buffer at $80{ }^{\circ} \mathrm{C}$ for $20 \mathrm{~min}$ resulted in equivalent results with a radiochemical purity of not less than $90 \%$ as determined by HPLC (Suppl Fig. 1) and ITLC-SG. This was considered as sufficient for this initial evaluation of $\left[{ }^{89} \mathrm{Zr}\right]$ siderophores, and the methods using sodium acetate buffer for Ga-68 as well as for Zr-89 labelling of siderophores were used for further in vitro and in vivo experiments.

\section{In Vitro Characterization}

All studied siderophores showed hydrophilic properties with partition coefficients $(\log P)$ ranging from -1.65 to -3.56 . FOXE and FCHA displayed very similar $\log P$ values for both Ga-68 and Zr-89 complexes, while TAFC and FOXB displayed more lipophilic character when labelled with $\mathrm{Zr}$ 89. Protein binding values did not exceed $11 \%$ for $\left[{ }^{68} \mathrm{Ga}\right]$ siderophores (incubation time $120 \mathrm{~min}$ ), whereas $\left[{ }^{89} \mathrm{Zr}\right] \mathrm{FOXE}$ and $\left[{ }^{89} \mathrm{Zr}\right] \mathrm{FCHA}$ showed 16.6 and $31.1 \%$ of protein binding after 24-h incubation period. All the $\left[{ }^{68} \mathrm{Ga}\right]$ siderophores were stable in vitro, with the exception of $\left[{ }^{68} \mathrm{Ga}\right]$ FOXB (Table 1). The stability studies of $\left[{ }^{89} \mathrm{Zr}\right]$ siderophores (Table 2) displayed some differences compared to $\left[{ }^{68} \mathrm{Ga}\right]$ siderophores. In particular, $\left[{ }^{89} \mathrm{Zr}\right] \mathrm{FCHA}$ was less stable as compared to its Ga-68 labelled counterpart whereas $\left[{ }^{89} \mathrm{Zr}\right] \mathrm{FOXB}$ revealed higher stability in all examined media.

\section{Ex Vivo Biodistribution in Balb/c Mice}

Ga-68 and Zr-89 labelled TAFC, FCHA and FOXB showed virtually identical ex vivo biodistribution in Balb/c mice. All six compounds were rapidly excreted via the renal system and showed minimal retention in blood and the various organs. $\left[{ }^{68} \mathrm{Ga}\right]$ FOXE revealed similar biodistribution with slightly higher radioactivity values in gastrointestinal tract compared to the other radiolabelled siderophores, whereas $\left[{ }^{89} \mathrm{Zr}\right] \mathrm{FOXE}$ showed significantly higher radioactivity accumulation in the intestines and liver. In all cases, $\left[{ }^{89} \mathrm{Zr}\right]$ siderophores displayed slightly higher bone uptake compared to their Ga-68 labelled counterparts, but always lower than $1 \% \mathrm{ID} / \mathrm{g}$, whereas there was a trend of higher blood activity for Ga-68 vs. $\left[{ }^{89} \mathrm{Zr}\right]$ compounds, both

Table 1. In vitro characterization of studied Ga-68 labelled siderophores. $\log P$, protein binding (expressed as $\%$ of protein bound activity of the total activity used) and stability (in human serum and $6 \mathrm{mM}$ DTPA) of $\left[{ }^{68} \mathrm{Ga}\right] \mathrm{TAFC},\left[{ }^{68} \mathrm{Ga}\right] \mathrm{FOXE},\left[{ }^{68} \mathrm{Ga}\right] \mathrm{FCHA}$ and $\left[{ }^{68} \mathrm{Ga}\right] \mathrm{FOXB}$

\begin{tabular}{|c|c|c|c|c|c|}
\hline$\left[{ }^{68} \mathrm{Ga}\right]$ siderophore & $\begin{array}{l}\log P \\
(\operatorname{mean} \pm \mathrm{SD}, n=6)\end{array}$ & Incubation time ( $\mathrm{min}$ ) & $\begin{array}{l}\text { Protein binding }(\%) \\
(\text { mean, } n=2)\end{array}$ & $\begin{array}{l}\text { Stability in human } \\
\text { serum }(\%)(n=1)\end{array}$ & $\begin{array}{l}\text { Stability in DTPA } \\
\text { solution }(\%)(n=1)\end{array}$ \\
\hline \multirow[t]{3}{*}[{}^{68}\mathrm{Ga}]{$\mathrm{TAFC}$} & \multirow[t]{3}{*}{$-2.59 \pm 0.15$} & 30 & 0.47 & 99.9 & 85.0 \\
\hline & & 60 & 0.76 & 99.9 & 84.7 \\
\hline & & 120 & 1.21 & 99.9 & 81.8 \\
\hline \multirow[t]{3}{*}[{}^{68}\mathrm{Ga}]{$\mathrm{FOXE}$} & \multirow[t]{3}{*}{$-1.65 \pm 0.03$} & 30 & 0.27 & 99.9 & 94.3 \\
\hline & & 60 & 0.24 & 99.9 & 93.8 \\
\hline & & 120 & 0.53 & 99.9 & 93.2 \\
\hline \multirow{3}{*}[{}^{68}\mathrm{Ga}]{$\mathrm{FCHA}$} & \multirow[t]{3}{*}{$-3.24 \pm 0.07$} & 30 & 5.12 & 97.4 & 97.7 \\
\hline & & 60 & 6.98 & 97.8 & 95.7 \\
\hline & & 120 & 4.21 & 98.5 & 92.3 \\
\hline \multirow[t]{3}{*}[{}^{68}\mathrm{Ga}]{$\mathrm{FOXB}$} & \multirow[t]{3}{*}{$-3.56 \pm 0.17$} & 30 & 7.67 & 74.1 & 60.1 \\
\hline & & 60 & 10.29 & 72.0 & 54.5 \\
\hline & & 120 & 10.83 & 75.4 & 52.9 \\
\hline
\end{tabular}


Table 2. In vitro characterization of studied $\mathrm{Zr}-89$ labelled siderophores. $\log P$, protein binding (expressed as \% of protein bound activity of the total activity used) and stability (in human serum and $6 \mathrm{mM}$ DTPA) of $\left[{ }^{89} \mathrm{Zr}\right] \mathrm{TAFC},\left[{ }^{89} \mathrm{Zr}\right] \mathrm{FOXE},\left[{ }^{89} \mathrm{Zr}\right] \mathrm{FCHA}$ and $\left[{ }^{89} \mathrm{Zr}\right] \mathrm{FOXB}$

\begin{tabular}{|c|c|c|c|c|c|}
\hline$\left[{ }^{89} \mathrm{Zr}\right]$ siderophore & $\begin{array}{l}\log P \\
(\operatorname{mean} \pm \mathrm{SD}, n=6)\end{array}$ & Incubation time (min) & $\begin{array}{l}\text { Protein binding (\%) } \\
\text { (mean, } n=2)\end{array}$ & $\begin{array}{l}\text { Stability in human } \\
\text { serum }(\%)(n=1)\end{array}$ & $\begin{array}{l}\text { Stability in DTPA } \\
\text { solution (\%) }(n=1)\end{array}$ \\
\hline \multirow[t]{3}{*}[{}^{89}\mathrm{Zr}]{$\mathrm{TAFC}$} & \multirow[t]{3}{*}{$-1.95 \pm 0.03$} & 1 & 0.99 & 98.08 & 99.51 \\
\hline & & 4 & 0.34 & 98.72 & 99.50 \\
\hline & & 24 & 1.37 & 98.50 & 99.50 \\
\hline \multirow[t]{3}{*}[{}^{89}\mathrm{Zr}]{$\mathrm{FOXE}$} & \multirow[t]{3}{*}{$-1.91 \pm 0.04$} & 1 & 3.27 & 98.07 & 99.70 \\
\hline & & 4 & 5.86 & 99.70 & 99.50 \\
\hline & & 24 & 16.59 & 98.34 & 99.70 \\
\hline \multirow[t]{3}{*}[{}^{89}\mathrm{Zr}]{$\mathrm{FCHA}$} & \multirow[t]{3}{*}{$-3.28 \pm 0.37$} & 1 & 2.70 & 92.76 & 68.70 \\
\hline & & 4 & 6.24 & 85.42 & 65.27 \\
\hline & & 24 & 31.05 & 77.38 & 54.22 \\
\hline \multirow{3}{*}[{}^{89}\mathrm{Zr}]{$\mathrm{FOXB}$} & \multirow[t]{3}{*}{$-3.01 \pm 0.07$} & 1 & 1.63 & 99.61 & 91.56 \\
\hline & & 4 & 2.05 & 99.70 & 90.39 \\
\hline & & 24 & 1.84 & 99.53 & 87.10 \\
\hline
\end{tabular}

indicating the behaviour of the free radionuclides. Ex vivo biodistribution data are presented in Fig. 2.

\section{Small Animal PET Imaging}

MicroPET imaging of Balb/c mice injected with Ga- 68 and $\mathrm{Zr}-89$ labelled TAFC and FOXB showed rapid clearance from the bloodstream with the major excretion route via kidneys. Both pairs of radiolabelled siderophores displayed very similar kinetics and biodistribution (Figs. 3 and 4). Significantly different in vivo behaviour was observed for the $\left[{ }^{68} \mathrm{Ga}\right] /$ $\left[{ }^{89} \mathrm{Zr}\right]$ FOXE pair. $\left[{ }^{68} \mathrm{Ga}\right]$ FOXE was quickly eliminated mainly via the kidneys with certain part of radioactivity excreted via the gastrointestinal tract, while $\left[{ }^{89} \mathrm{Zr}\right] \mathrm{FOXE}$ revealed much slower kinetics and significant hepatobiliary elimination. Animal imaging data confirmed and supplemented the data from ex vivo biodistribution studies. The representative imaging data is presented in Figs. 3 and 4.

\section{Discussion}

Until recently, the majority of preclinical and clinical research has focused on the development of PET radiopharmaceuticals using conventional PET radionuclides such as C-11, N-13, O-15 and F-18 [18]. This has changed with the increased availability and production of non-conventional positron-emitting radionuclides such as $\mathrm{Cu}-64, \mathrm{Ga}-68, \mathrm{Y}-86, \mathrm{Zr}-89$ and I-124. Recently, Ga68 and $\mathrm{Zr}-89$ have generated significant interest in the nuclear medicine community with a concomitant increase in the use of Ga-68 labelled peptides for PET imaging of neuroendocrine tumours and Zr-89 imunoPET [8, 19].

The radiolabelling of biomolecules with $\mathrm{Zr}-89$ is usually performed by the desferrioxamine $\mathrm{B}$ (FOXB) chelator, commercially available as Desferal. FOXB is a hexadentate siderophore containing three hydroxamate groups for chelating metals and a primary amine functional group for conjugation to a biomolecule. It is a chelating agent for several metal ions besides $\mathrm{Zr}-89$ [20]. Zr-89 radiolabelling of biomolecules using the FOXB chelator has shown that the in vivo stability of this complex remains an issue. This instability has been observed in several preclinical studies with uptake of $\mathrm{Zr}$ 89 in bones [21, 22]. While many investigators have focused on the modification of the linkage between the FOXB and the biomolecule [23, 24], others have attempted to improve the chelator itself [25-29]. Despite these attempts, a novel high-stability $\mathrm{Zr}^{4+}$ ligand which would minimize the uptake of liberated $\mathrm{Zr}^{4+}$ in the bone and other non-targeted tissue is warranted.

In this study, we have investigated the in vitro and in vivo behaviour of selected hydroxamate siderophores labelled with $\mathrm{Zr}-89$ to evaluate their potential to be used as novel $\mathrm{Zr}-89$ chelators and to compare their in vitro and in vivo properties with their Ga-68 labelled counterparts. We note that studied siderophores are only hexadentate ligands and cannot coordinatively saturate $\mathrm{Zr}^{4+}$ that can bind up to eight ligand atoms. Therefore, it is to be expected that the additional positive charge of $\mathrm{Zr}^{4+}$ will have a pronounced effect on chemical and biological properties of small chelators such as siderophores. However, the complexation of $\mathrm{Zr}^{4+}$ is affected not only by number of coordinating atoms but also by linear vs. cyclic character, optimal ring size and appropriate geometry of the ligand [26].

Triacetylfusarinine $\mathrm{C}$ (TAFC) and ferrioxamine E (FOXE) are macrocyclic hydroxamate siderophores with the ring size of 35 (TAFC) and 33 (FOXE) atoms, which is deemed to be in the appropriate range for $\mathrm{Zr}^{4+}$ chelation to preserve the optimal spatial orientation [25]. These siderophores were chosen due to their successful application as Ga-68 labelled tracers in the imaging of Aspergillus infection in rats [7]. We aimed to further test the ability of $\mathrm{Zr}-89$ to label these promising 
M. Petrik et al.: Comparison of Ga-68 and $\left[{ }^{89} \mathrm{Zr}\right]$ siderophores

349
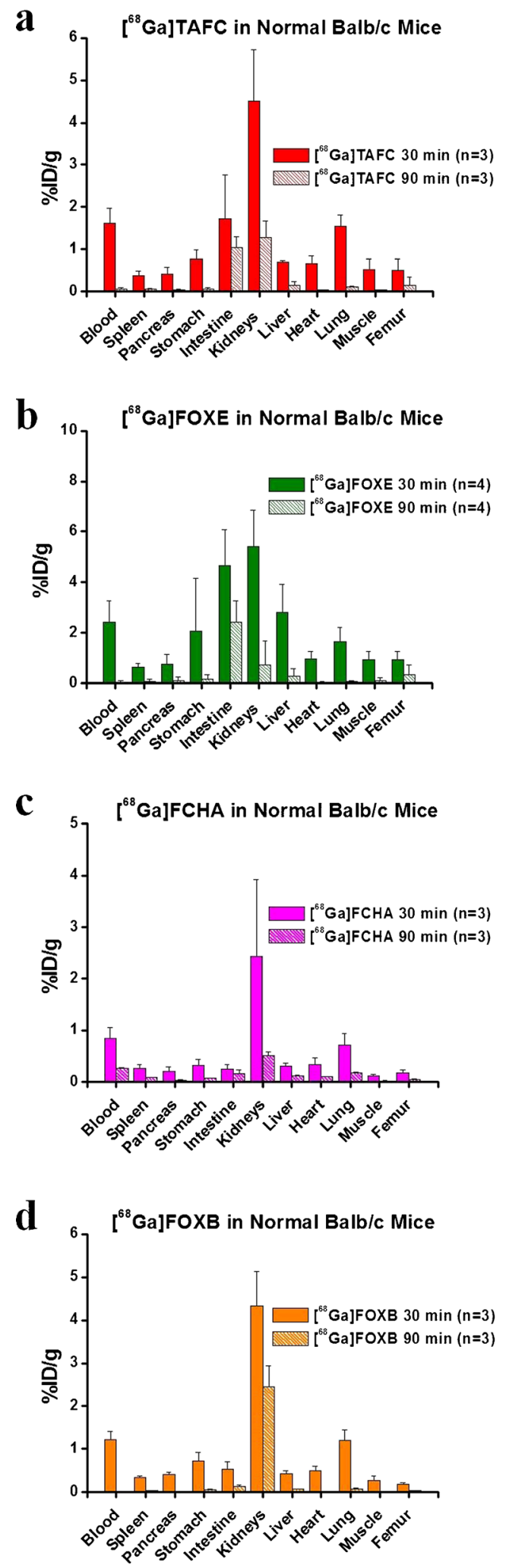
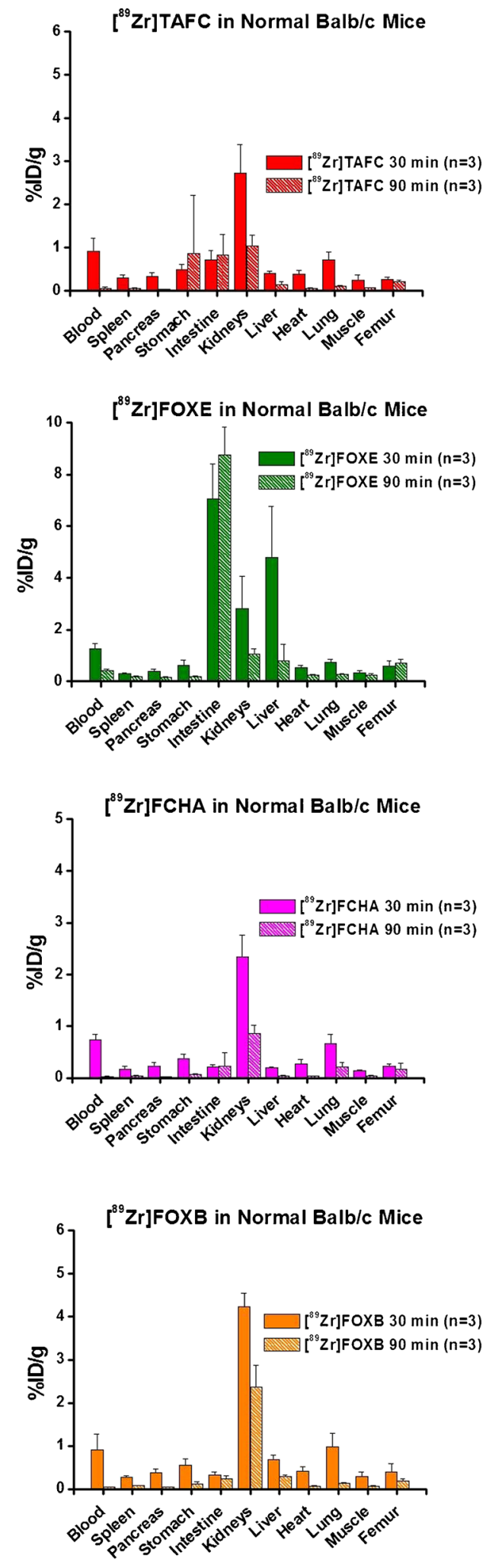

Fig. 2 Ex viva biodistribution of studied radiolabelled siderophores in Balb/c mice 30 and 90 min pi. Data are presented as percentage of injected dose per gram organ $(\% \mathrm{ID} / \mathrm{g} \pm \mathrm{SD} ; n=3)$.

infection imaging agents in order to enlarge their imaging time frame for imaging Aspergillus infection, e.g., for treatment monitoring. Ferrichrome A (FCHA) and FOXB are representatives of linear hydroxamate siderophores. FOXB was selected as a standard chelating agent used in nuclear medicine for Zr-89 labelling. 

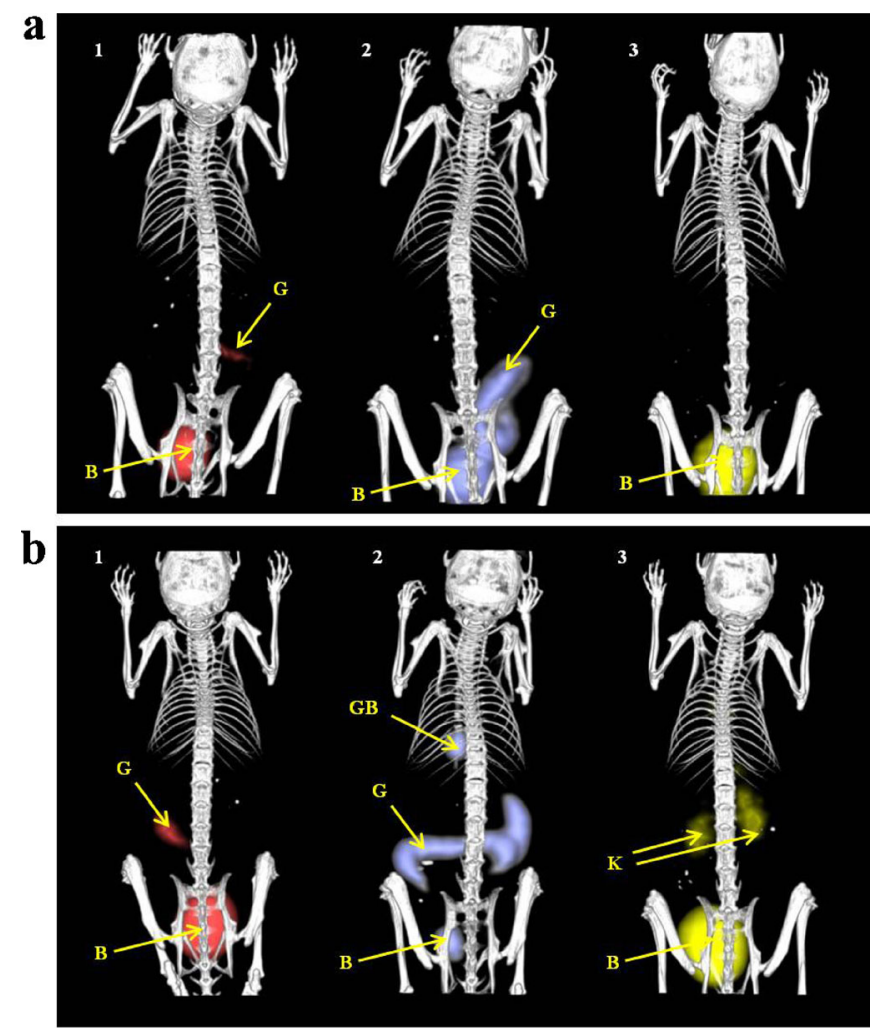

Fig. $33 \mathrm{D}$ volume rendered images of static $\mu \mathrm{PET} / \mathrm{CT}$ imaging of $\left[{ }^{68} \mathrm{Ga}\right]$ siderophores $(\mathrm{a}-\mathrm{TAFC}=1, \mathrm{FOXE}=2, \mathrm{FOXB}=3)$ and $\left[{ }^{89} \mathrm{Zr}\right.$ ]siderophores (b-TAFC=1, FOXE=2, FOXB=3) 90 min p.i. (supine position; injected dose, 5-10 MBq; anaesthesia, $2 \%$ isoflurane; scan duration, 5 min PET scan followed by 20 min CT scan; $B$ —bladder, $G$ — gastrointestinal tract, GB-gall bladder, $K$-kidney).

All siderophores that were tested could be labelled to near-completeness with both Ga-68 and Zr-89 using established labelling protocols. Both Ga-68 and Zr-89 labelled siderophores showed hydrophilic properties with $\left[{ }^{89} \mathrm{Zr}\right]$ siderophores having a tendency to be slightly more lipophilic. This is rather surprising, as the binding of $\mathrm{Ga}^{3+}$ results in a neutral molecule, whereas $\mathrm{Zr}^{4+}$ introduces an additional positive charge. Significant differences among studied siderophores were observed mainly in protein binding and in vitro stability. $\left[{ }^{68} \mathrm{Ga}\right] \mathrm{TAFC},\left[{ }^{68} \mathrm{Ga}\right] \mathrm{FOXE}$ and $\left[{ }^{68} \mathrm{Ga}\right] \mathrm{FCHA}$ displayed identical or lesser protein binding abilities than their $\mathrm{Zr}-89$ labelled counterparts, while $\left[{ }^{68} \mathrm{Ga}\right]$ FOXB revealed higher protein binding values in comparison with $\left[{ }^{89} \mathrm{Zr}\right] \mathrm{FOXB}$. It could be speculated that the change of cation in the complex with difference in charge leads to a more amphiphilic character resulting in higher binding to plasma proteins or possibly phospholipids, but more experimental data would be required to support such a hypothesis. Ga-68 labelled cyclic hydroxamate siderophores (TAFC and FOXE) and $\left[{ }^{68} \mathrm{Ga}\right] \mathrm{FCHA}$ were very stable in all tested media, whereas $\left[{ }^{68} \mathrm{Ga}\right] \mathrm{FOXB}$ showed pronounced in vitro instability. The in vitro stability of studied $\left[{ }^{89} \mathrm{Zr}\right]$ siderophores was different in some aspects. For instance, $\left[{ }^{89} \mathrm{Zr}\right] \mathrm{FOXB}$ displayed a much higher in vitro stability than $\left[{ }^{68} \mathrm{Ga}\right] \mathrm{FOXB}$. Ex vivo biodistribution and small animal imaging of all Ga-68 and Zr-89 labelled siderophores injected into Balb/c mice displayed similar pharmacokinetics and minimal accumulation of radioactivity in blood and other organs and tissues with the exception of $\left[{ }^{89} \mathrm{Zr}\right] \mathrm{FOXE}$, which caused significant retention of radioactivity in the gastrointestinal tract. In all cases, $\left[{ }^{89} \mathrm{Zr}\right]$ siderophores displayed slightly higher (90 min p.i.), but still very low, retention of radioactivity in bones, indicating favourable in vivo stability in the studied time intervals. The differences in the behaviour of Ga-68 and the corresponding $\left[{ }^{89} \mathrm{Zr}\right]$ siderophores could be explained by the different charge of the two radio-metal ions, resulting in a positively charged complex for hydroxamate coordinations for $\mathrm{Zr}$ in contrast to a neutral overall charge in the case of Ga. Even though there was no obvious instability of $\mathrm{Zr}-89$ compounds, further investigations are required especially in the view of a higher stability of $\mathrm{Zr}$-complexes by using octacoordinating ligands [25, 28].

The overall comparable properties of Ga-68 and Zr-89 labelled siderophores (despite the differences of $\mathrm{Ga}$ and $\mathrm{Zr}$ in terms of charge, coordination chemistry and ionic radius) warrant further investigation of the targeting behaviour of Zr-89 labelled siderophores. This is of high interest in the application of the radiolabelled siderophores in the imaging of infection, in particular, infection by invasive fungal pathogens. The preclinical monitoring of therapy could benefit from a radionuclide that has a longer half-life, as it 

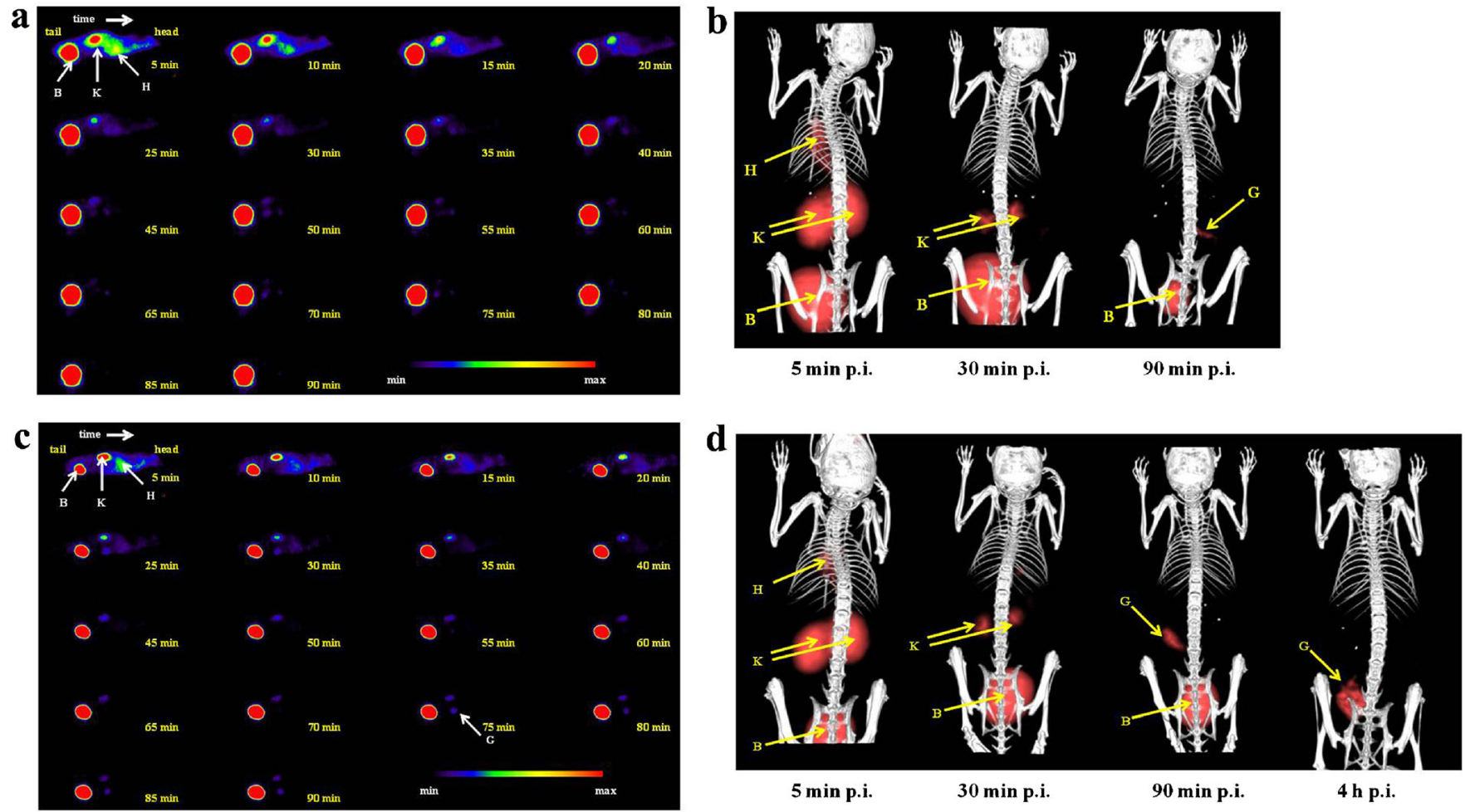

Fig. $4 \mu \mathrm{PET} / \mathrm{CT}$ imaging of $\left[{ }^{68} \mathrm{Ga}\right] \mathrm{TAFC}$ and $\left[{ }^{89} \mathrm{Zr}\right] \mathrm{TAFC}$ in Balb/c mice: dynamic PET imaging of $\left[{ }^{68} \mathrm{Ga}\right] \mathrm{TAFC}(\mathbf{a})$, static PET/CT imaging of $\left[{ }^{68} \mathrm{Ga}\right]$ TAFC (b), dynamic PET imaging of $\left[{ }^{89} \mathrm{Zr}\right] \mathrm{TAFC}(\mathbf{c})$, static PET/CT imaging of [ $\left.{ }^{89} \mathrm{Zr}\right] \mathrm{TAFC}$ (d). (Sagittal slices (a, c) and $3 \mathrm{D}$ volume rendered images (b, d); injected dose, 5-10 MBq; anaesthesia, $2 \%$ isoflurane; scan duration, dynamic imaging=5 min PET scan per frame (18 frames); static imaging=5 min PET scan followed by 20 min CT scan; $B-$ bladder, $G$-gastrointestinal tract, $H$-heart, $K$-kidney).

would enable longer imaging times (from minutes to days). However, there is no data available so far that proves that $\left[{ }^{89} \mathrm{Zr}\right]$ siderophores such as TAFC are recognized by the specific transporters of microorganisms in the same way as their Ga-68 labelled counterparts [7, 15]. Further studies in this respect are ongoing. The other application could lie in the development of novel, more stable $\left[{ }^{89} \mathrm{Zr}\right]$ bioconjugates, coupling siderophores to, e.g., receptor of antigen targeting sequences. Here, the difference of Zr-89 vs. Ga-68 labelling will not result in a difference in targeting properties, but may result in different pharmacokinetics due to changes in charge and resulting lipophilicity. In this regard, preliminary studies of fusarinine $\mathrm{C}$ (FSC)-based bioconjugates that have been described recently for Ga-68 labelling [30] and $\mathrm{Zr}-89$ labelling [31] showed excellent in vivo stabilities and tumour targeting.

\section{Conclusion}

We have shown in this study that a variety of siderophores can be labelled with Ga-68 and Zr-89. Ga-68 and $\left[{ }^{89} \mathrm{Zr}\right]$ siderophores displayed analogous, but not fully identical in vitro and in vivo behaviour. Ga- $68^{3+}$ seems to be the more suitable radionuclide for labelling of hexadentate hydroxamate siderophores. Nevertheless, $\left[{ }^{89} \mathrm{Zr}\right] \mathrm{TAFC}$ showed favourable properties for potential longitudinal
Aspergillus infection imaging using the animal model from our previous studies, and also availability as a model structure for preparation of novel bioconjugates.

Acknowledgments. We would like to thank the staff of the Animal Facilities of Institute of Molecular and Translational Medicine of Faculty of Medicine and Dentistry of Palacky University in Olomouc. We gratefully acknowledge the financial support of National Programme of Sustainability LO1304 (to M.P. and Z.N.) and LO1204 (to L.U.), Technology Agency of the Czech Republic (project No. TE01020028 to M.P.), Internal Grant Agency of Palacky University (project No. IGA_LF_2015_010 to M.P.) and the Austrian Science Foundation (FWF; grant P $25899-\mathrm{B} 23$ to C.D.).

Compliance with Ethical Standards.

Conflict of Interest Statement. The authors declare that they have no conflict of interest.

Open Access This article is distributed under the terms of the Creative Commons Attribution 4.0 International License (http://creativecommons.org/ licenses/by/4.0/), which permits unrestricted use, distribution, and reproduction in any medium, provided you give appropriate credit to the original author(s) and the source, provide a link to the Creative Commons license, and indicate if changes were made.

\section{References}

1. Neilands JB (1995) Siderophores: structure and function of microbial iron transport compounds. J Biol Chem 270:26723-26726

2. Hider RC, Kong X (2010) Chemistry and biology of siderophores. Nat Prod Rep 27:637-657

3. Cassat JE, Skaar EP (2013) Iron in infection and immunity. Cell Host Microbe 13:509-519 
4. Haas H (2014) Fungal siderophore metabolism with a focus on Aspergillus fumigatus. Nat Prod Rep 31:1266-1276

5. Ali SS, Vidhale NN (2013) Bacterial siderophore and their application: a review. Int J Curr Microbiol App Sci 2:303-312

6. Miethke M, Marahiel MA (2007) Siderophore-based iron acquisition and pathogen control. Microbiol Mol Biol Rev 71:413-451

7. Petrik M, Franssen GM, Haas H et al (2012) Preclinical evaluation of two ${ }^{68} \mathrm{Ga}$-siderophores as potential radiopharmaceuticals for Aspergillus fumigatus infection imaging. Eur J Nucl Med Mol Imaging 39:1175-1183

8. Velikyan I (2014) Prospective of ${ }^{68}$ Ga-radiopharmaceutical development. Theranostics 4:47-80

9. Decristoforo C (2012) Gallium-68 - a new opportunity for PET available from a long shelf-life generator-automation and applications. Curr Radiopharm 5:212-220

10. Radchenko V, Busse S, Roesch F (2014) Desferrioxamine as an appropriate chelator for ${ }^{90} \mathrm{Nb}$ : comparison of its complexation properties for M-Df-Octreotide (M=Nb, Fe, Ga, Zr). Nucl Med Biol 41:721-727

11. Fischer G, Seibold U, Schirrmacher R et al (2013) ${ }^{89} \mathrm{Zr}$, a radiometal nuclide with high potential for molecular imaging with PET: chemistry, applications and remaining challenges. Molecules 18:6469-6490

12. Holland JP, Sheh YC, Lewis JS (2009) Standardized methods for the production of high specific-activity zirconium-89. Nucl Med Biol 36:729-739

13. Van Dongen GAMS, Visser GWM, Hooge MNLD et al (2007) Immuno-PET: a navigator in monoclonal antibody development and applications. Oncologist 12:1379-1389

14. Petrik M, Haas H, Schrettl M, Helbok A, Blatzer M, Decristoforo C (2012) In vitro and in vivo evaluation of selected ${ }^{68} \mathrm{Ga}$-siderophores for infection imaging. Nucl Med Biol 39:361-369

15. Petrik M, Haas H, Dobrozemsky G et al $(2010){ }^{68} \mathrm{Ga}$-siderophores for PET imaging of invasive pulmonary aspergillosis: proof of principle. J Nucl Med 51:639-645

16. Petrik M, Haas H, Laverman $P$ et al (2014) ${ }^{68}$ Ga-triacetylfusarinine $C$ and ${ }^{68} \mathrm{Ga}$-ferrioxamine $\mathrm{E}$ for Aspergillus infection imaging: uptake specificity in various microorganisms. Mol Imaging Biol 16:102-108

17. Deri MA, Zeglis BM, Francesconi LC, Lewis JS (2013) PET imaging with ${ }^{89} \mathrm{Zr}$ : from radiochemistry to the clinic. Nucl Med Biol 40:3-14

18. Holland JP, Williamson MJ, Lewis JS (2010) Unconventional nuclides for radiopharmaceuticals. Mol Imaging 9:1-20

19. Van Dongen GA, Vosjan MJ (2010) Immuno-positron emission tomography: shedding light on clinical antibody therapy. Cancer Biother Radiopharm 25:375-385
20. Kiss T, Farkas E (1998) Metal-binding ability of desferrioxamine B. J Incl Phenom Mol Recog Chem 32:385-403

21. Holland JP, Divilov V, Bander NH et al (2010) ${ }^{89}$ Zr-DFO-J591 for immunoPET of prostate-specific membrane antigen expression in vivo. J Nucl Med 51:1293-1300

22. Van Rij CM, Sharkey RM, Goldenberg DM, Frielink C et al (2011) Imaging of prostate cancer with immuno-PET and immuno-SPECT using a radiolabeled anti-EGP-1 monoclonal antibody. J Nucl Med 52:1601-1607

23. Verel I, Visser GW, Boellaard $\mathrm{R}$ et al (2003) ${ }^{89} \mathrm{Zr}$ immuno-PET: comprehensive procedures for the production of ${ }^{89} \mathrm{Zr}$-labeled monoclonal antibodies. J Nucl Med 44:1271-1281

24. Perk L, Vosjan MWD, Visser GM et al (2010) p-Isothiocyanatobenzyldesferrioxamine: a new bifunctional chelate for facile radiolabeling of monoclonal antibodies with zirconium-89 for immuno-PET imaging. Eur J Nucl Med Mol Imaging 37:250-259

25. Guerard F, Lee YS, Tripier R et al (2013) Investigation of Zr(IV) and ${ }^{89} \mathrm{Zr}(\mathrm{IV})$ complexation with hydroxamates: progress towards designing a better chelator than desferrioxamine B for immuno-PET imaging. Chem Commun 49:1002-1004

26. Guérard F, Lee YS, Brechbiel MW (2014) Rational design, synthesis, and evaluation of tetrahydroxamic acid chelators for stable complexation of zirconium (IV). Chem Eur J 20:5584-5591

27. Deri MA, Ponnala S, Zeglis BM et al (2014) An alternative chelator for ${ }^{89} \mathrm{Zr}$ radiopharmaceuticals: radiolabeling and evaluation of 3,4,3-(LI-1, 2-HOPO). J Med Chem 57:4849-4860

28. Patra M, Bauman A, Mari C et al (2014) An octadentate bifunctional chelating agent for the development of stable zirconium-89 based molecular imaging probes. Chem Commun $50: 11523-11525$

29. Ma MT, Meszaros LK, Paterson BM et al (2015) Tripodal tris (hydroxypyridinone) ligands for immunoconjugate PET imaging with ${ }^{89} \mathrm{Zr}^{4+}$ : comparison with desferrioxamine-B. Dalton Trans 44:48844900

30. Knetsch PA, Zhai C, Rangger $C$ et al (2015) $\left[{ }^{68}\right.$ Ga]FSC-(RGD)3 a trimeric RGD peptide for imaging $\alpha \mathrm{v} \beta 3$ integrin expression based on novel siderophore derived chelating scaffold - synthesis and evaluation. Nucl Med Biol 42:115-122

31. Zhai C, Summer D, Rangger C et al (2015) Novel bifunctional cyclic chelator for ${ }^{89} \mathrm{Zr}$ labelling-radiolabeling and targeting properties of RGD conjugates. Mol Pharmaceut 12:2142-2150 